\title{
Thermo-analytical evaluation of wear debris for thermoplastic and sintered polyimide
}

\author{
P. Samyn ${ }^{1}$, I. Van Driessche ${ }^{2}$, G. Schoukens ${ }^{3} \&$ P. De Baets ${ }^{1}$ \\ ${ }^{I}$ Department of Mechanical Construction and Production, \\ Ghent University, Belgium \\ ${ }^{2}$ Department of Inorganic and Physical Chemistry, \\ Ghent University, Belgium \\ ${ }^{3}$ Department of Textiles, Ghent University, Belgium
}

\begin{abstract}
Transitions in friction and wear properties for polyimides are related to thermogravimetric analysis (TGA), differential thermal analysis (DTA) and mass spectroscopy (MS) of wear debris particles. Debris interactions in the sliding interface are important for the formation of a transfer film on the counterface. For sintered polyimide, fine wear debris particles are observed after sliding at 100 to $180^{\circ} \mathrm{C}$, corresponding to high friction and lack of transfer. Conglomerated particles at 180 to $260^{\circ} \mathrm{C}$ coincide with a drop in friction and stabilisation in wear rates. Chemical reactions in the sliding interface such as hydrolysis and imidisation are illustrated. For thermoplastic polyimide, dark-coloured particles after 100 to $120^{\circ} \mathrm{C}$ sliding indicate hydrolysis, flake-like particles after 120 to $180^{\circ} \mathrm{C}$ sliding indicate imidisation and roll-like debris at 220 to $260^{\circ} \mathrm{C}$ show melting. It is confirmed by DTA that the glass transition and recrystallisation temperatures shift or disappear depending on the sliding temperature, representing the formation of cross-links and better ordered crystalline phase under sliding. Debris becomes brittle and consequently acts more abrasive during sliding.
\end{abstract}

Keywords: polyimide, tribology, wear debris, differential thermal analysis, thermogravimetric analysis, mass spectroscopy, hydrolysis, imidisation.

\section{Introduction}

Polyimides are used in sliding contacts with steel counterfaces because of their self-lubricating effect. This means that no external lubricants such as oil or 
grease are necessary. The lubricating mechanisms of polymers are attributed to the formation of a polymer transfer film adhering to the steel counterface and reversing the polymer/steel contact into polymer/polymer contact. In literature, the role of wear debris in establishing a transfer film is mainly described mechanically (e.g. Jacko et al. [1]). The roughness asperities of the steel counterface act as mechanical anchor points for accumulation of wear debris. However, homogenisation of the transfer film depends on interaction of the separate wear debris particles by thermal or chemical processes. Most reported polymer sliding mechanisms focus on melting of the polymer surface. To get better insight in the sliding mechanisms, however, a close evaluation of wear debris particles can provide additional information. Due to the joint action of repeated shear and high temperature, the wear debris particles undergo physical and chemical reactions since its generation. As a result, the properties of those small particles would not be identical to those of the bulk material and are characteristic for the wear process. The transitions between glass and rubbery phase occur at specific temperatures and crystallisation during sliding affects the melting behaviour. Also degradation mechanisms as melting, oxidation and pyrolysis take place and further control the sliding stability, possibly leading to severe wear. Thermo-analytical analysis methods common to polymer science attracted the attention of only few researchers for better understanding of the changes in polymer structure under sliding (e.g. Sharf and Singer [2]). Presently, debris of thermoplastic polyimide (melting temperature $T_{m}=385^{\circ} \mathrm{C}$ ) and sintered polyimide (no melting temperature) after sliding at 60 to $260^{\circ} \mathrm{C}$ is evaluated for demonstrating that transitions in sliding are explained by chemical reactions below the melting temperature.

\section{Friction and wear testing}

Sintered polyimide (SP) and thermoplastic polyimide (TP) cylinders were slid in a line contact against high-alloy steel counterfaces (DIN 1.2738) under $50 \mathrm{~N}$ normal load and $0.3 \mathrm{~m} / \mathrm{s}$ sliding velocity on a universal reciprocating Plint TE 77 tribotester. The temperature of the steel counterface was controlled at 60 to $260^{\circ} \mathrm{C}$. An average coefficient of friction $\left(\mu=F_{\mathrm{f}} / F_{\mathrm{n}}\right.$ with $F_{\mathrm{f}}$ the horizontal friction force and $F_{\mathrm{n}}$ the normal load) after different sliding distances and the wear rates at the end of test (determined from weight loss) are shown in Figure 1 and Figure 2. For sintered polyimides, there are two sliding regimes with high friction at 60 to $180^{\circ} \mathrm{C}$ and low friction at 180 to $260^{\circ} \mathrm{C}$. The wear rates are minimum at $140^{\circ} \mathrm{C}$ and stabilise at higher temperature. For thermoplastic polyimides, there is a regime with increasing friction at 100 to $120^{\circ} \mathrm{C}$, a regime with decreasing friction at 120 to $180^{\circ} \mathrm{C}$ and a regime with overload at higher temperature due to melting. The transitions in friction coincide with transitions in wear behaviour. Besides the mentioned bulk temperature, also the maximum polymer surface temperature $\mathrm{T}^{*}$ is calculated from the frictional heat input. 
(a)

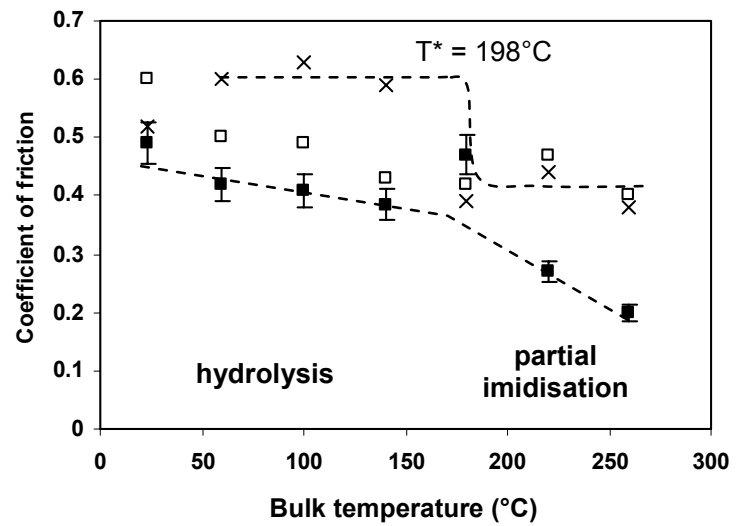

(b)

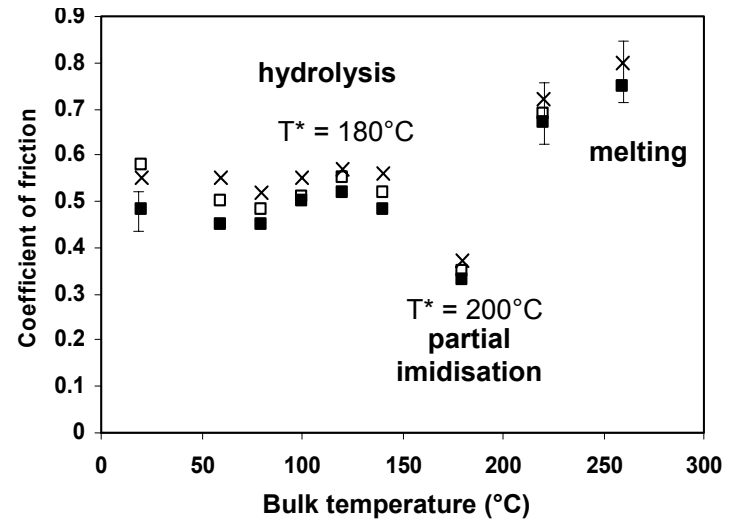

Figure 1: Overview of friction as a function of bulk temperature for (a) SP, and (b) TP, after $30 \mathrm{~m}(\mathbf{x}), 100 \mathrm{~m}(\square)$ and $15000 \mathrm{~m}$ or end-of-test (a).

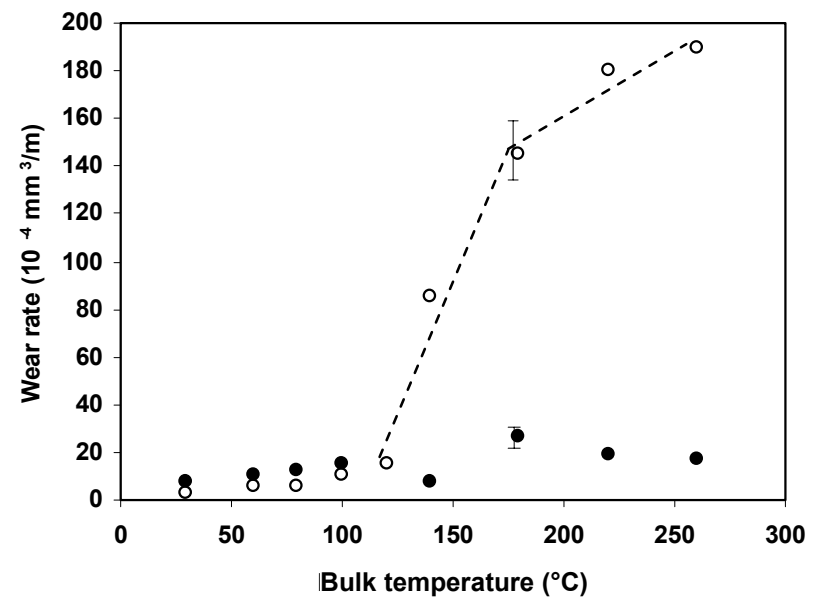

Figure 2: Overview of wear rates as a function of bulk temperature for SP $(\bullet)$ and TP (O). 


\section{Thermo-analytical analysis of sintered wear debris}

From literature (e.g. Tewari and Bijwe [3]), the colour of thermoplastic polyimide wear debris varied with increasing temperature and became very dark near wear peaks, suggesting that thermal decomposition was the main degradation mechanism. Comparing the maximum polymer surface temperatures $\mathrm{T}^{*}$ and degradation region of 500 to $700^{\circ} \mathrm{C}$ for sintered polyimide reveals, however, that transitions are not caused by thermal degradation but rather by chemical and/or physical changes. The morphology of sintered SP debris (Figure 3) shows small particles after sliding at $100^{\circ} \mathrm{C}$ (adhesive wear), conglomerated smooth particles above $180^{\circ} \mathrm{C}$ (chemical reaction in the interface) and some debris with original sintered structure at $260^{\circ} \mathrm{C}$ (mechanical overload by brittleness).

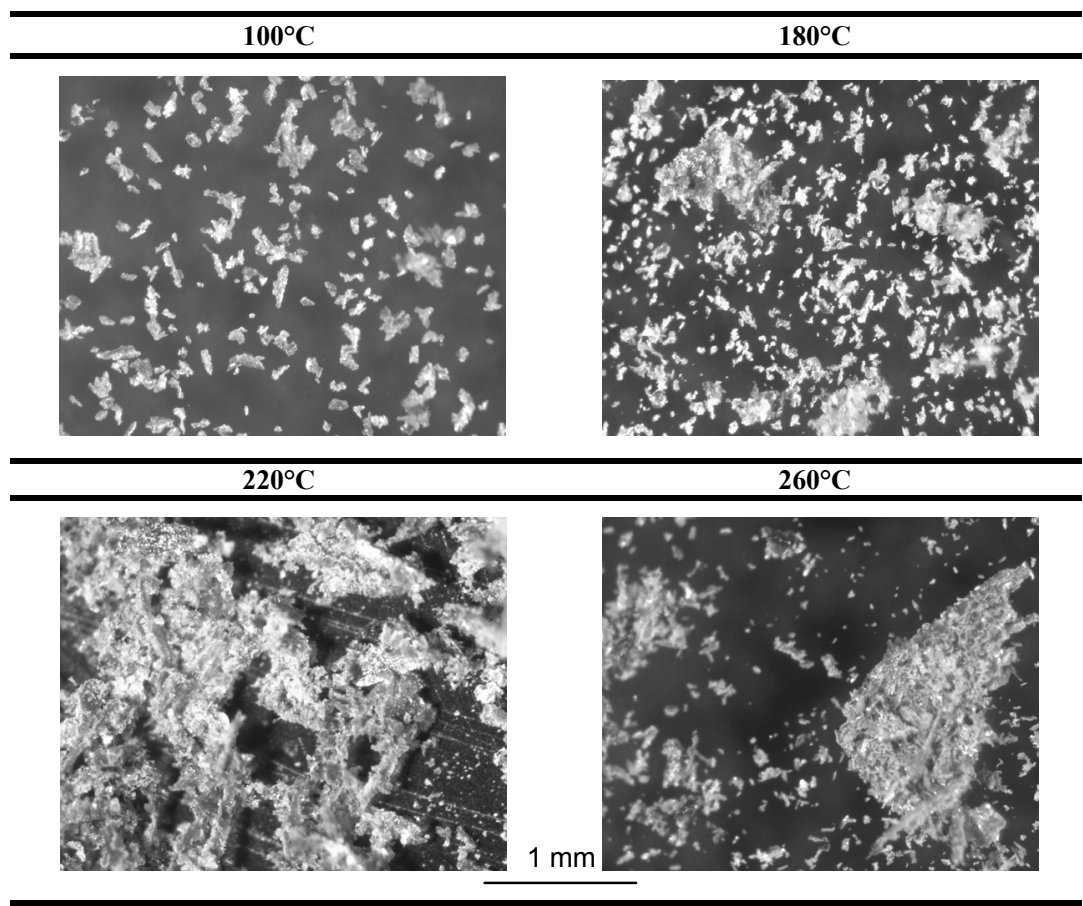

Figure 3: Optical microscopy of sintered polyimide SP wear debris after sliding at high temperature, $50 \mathrm{~N}, 0.3 \mathrm{~m} / \mathrm{s}$.

Thermo-analytical DTA/TGA analysis of wear debris particles $(3 \mathrm{mg})$ is made on a Stanton Redcroft 1500 Thermobalance to identify changes in thermal stability, weight loss and position of the endotherm peak (Figure 4, Table 1). Measurements indicate that debris particles imidised in the interface during the frictional process at $\mathrm{T}^{*}>180^{\circ} \mathrm{C}$. Two subsequent heating cycles from 23 to 
$450^{\circ} \mathrm{C}$ and 23 to $590^{\circ} \mathrm{C}$ at $20^{\circ} \mathrm{C} / \mathrm{min}$ are applied in nitrogen atmosphere, showing less variation compared to original polyimide through homogenisation under heating.

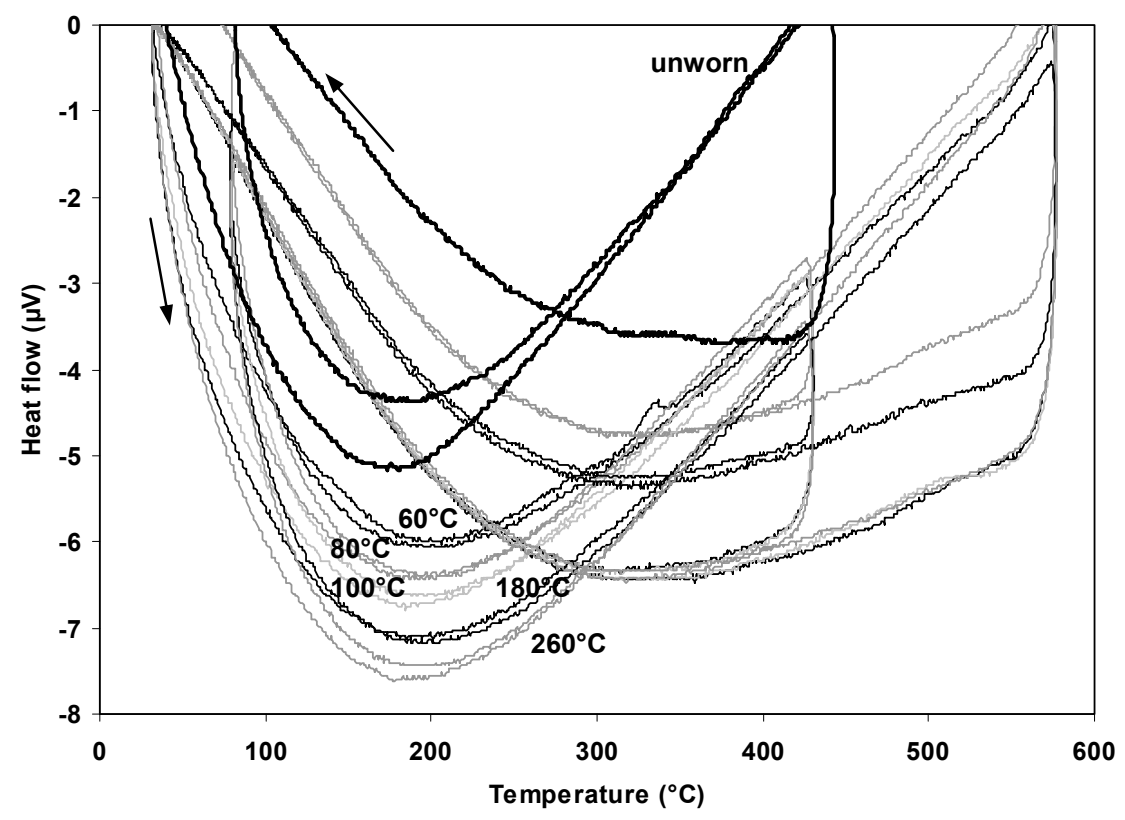

Figure 4: Differential thermal analysis (DTA) of SP wear debris after sliding at 60 to $260^{\circ} \mathrm{C}$.

No significant thermal degradation of the SP-1 wear debris is noted: the debris weight loss for each sliding temperature is restricted to $2 \%$ during the first heating cycle. The weight loss during the second heating cycle is higher and solely concentrated at 450 to $590^{\circ} \mathrm{C}$. The endotherm peak temperature or dehydration temperature $T_{\text {hydrat }}$ (maximum dehydration intensity) is determined from fitting curves in Figure 4 and it shifts towards higher temperatures for wear debris relatively to the unworn SP. The dehydration reaction of wear products depends on sliding temperature and normal loads: there is a general trend that the dehydration temperature increases for high sliding temperatures while this trend is stronger for high normal loads; at low loads, however, a critical bulk temperature of $180^{\circ} \mathrm{C}$ must be exceeded to increase the dehydration temperature. The upward shift in dehydration temperature of wear debris indicates chemical changes after sliding, such as imidisation, that cause a delay in dehydration. After formation of polyimide networks modified by sliding, higher temperatures or activation energy is needed for dehydration. Nevertheless, this process remains reversible during subsequent heating-cooling-heating cycles. According to Nagai [4] it is known that polyimides are sensitive to water absorption, but its relation to polyimide structures that are modified by wear was not yet illustrated. 
Table 1: $\quad$ TGA weight loss and DTA endotherm peak position of SP wear debris after sliding at 50 and $200 \mathrm{~N}, 0.3 \mathrm{~m} / \mathrm{s}$ at high temperature.

\begin{tabular}{|c|c|c|c|c|c|c|}
\hline \multirow{2}{*}{$\begin{array}{c}\text { Bulk } \\
\text { temperature } \\
\left({ }^{\circ} \mathrm{C}\right)\end{array}$} & \multicolumn{2}{|c|}{$50 \mathrm{~N}$ normal load sliding test } & \multicolumn{3}{c|}{$200 \mathrm{~N}$ normal load sliding test } \\
\cline { 2 - 3 } & \multicolumn{2}{|c|}{ Weight loss (\%) } & \multirow{2}{*}{$\begin{array}{c}T_{\text {hydrat }} \\
\left({ }^{\circ} \mathrm{C}\right)\end{array}$} & \multicolumn{2}{|c|}{ Weight loss $(\%)$} & \multirow{2}{*}{$T_{\text {hydrat }}\left({ }^{\circ} \mathrm{C}\right)$} \\
\cline { 2 - 3 } & $\begin{array}{c}1^{\text {st }} \\
\text { heating* }\end{array}$ & $\begin{array}{c}2^{\text {nd }} \\
\text { heating* }\end{array}$ & & $\begin{array}{c}1^{\text {st }} \\
\text { heating* }\end{array}$ & $\begin{array}{c}2^{\text {nd }} \\
\text { heating* }\end{array}$ & \\
\hline original & 0.72 & 13 & 182 & 0.72 & 13 & 182 \\
\hline $60^{\circ} \mathrm{C}$ & 0.64 & 16 & 204 & 1.45 & 32 & 200 \\
\hline $100^{\circ} \mathrm{C}$ & 1.51 & 18 & 199 & 1.82 & 32 & 220 \\
\hline $180^{\circ} \mathrm{C}$ & 1.59 & 18 & 192 & 0.94 & 31 & 222 \\
\hline $220^{\circ} \mathrm{C}$ & 1.15 & 18 & 197 & 0.23 & 30 & 228 \\
\hline $260^{\circ} \mathrm{C}$ & 1.20 & 18 & 200 & 0.20 & 30 & 230 \\
\hline
\end{tabular}

${ }^{*}$ First heating between 23 to $430^{\circ} \mathrm{C}$, second heating between 23 to $590^{\circ} \mathrm{C}$

\section{Thermo-analytical analysis of thermoplastic wear debris}

The variations in the structure of thermoplastic polyimide wear debris are more important than for sintered polyimides and can be well-correlated to different transitions in friction and wear. It mainly indicates thermal changes in the amorphous phase through crystallisation and/or cross-linking. The shift in dehydration temperature at $180^{\circ} \mathrm{C}$ as noted for sintered polyimides is less clear for thermoplastics through interference with complex phase changes.

Thermo-analytical DTA measurements of TP debris under similar conditions to $\mathrm{SP}$ are presented in Figure 5, during a first heating step $\left(23\right.$ to $\left.450^{\circ} \mathrm{C}\right)$ and a second heating step $\left(23\right.$ to $\left.590^{\circ} \mathrm{C}\right)$ at $20^{\circ} \mathrm{C} / \mathrm{min}$. The corresponding TGA curves are given in Figure 6 . The original TP has clear transition temperatures, but they smoothen for wear debris. Chemical reactions progressively change the thermoplastic polyimide structure into the properties of sintered polyimides that lack transitions and/or melting. Both sintering and/or sliding are thus considered as a 'thermal treatment' altering the polymer structure.

The first heating step in DTA (Figure 5(a)) shows that the glass transition temperature $T_{g}$ increases or finally disappears when it becomes smoothened over a broad interval from 230 to $280^{\circ} \mathrm{C}$. The glass transition temperature $T_{g}$ is representative for linear molecular structures in an amorphous ordering and shifting or disappearance indicates that the amorphous zone is affected by crosslinking into the formation of a more stable and ordered structure after sliding at high temperature. This evolution is also reflected in the disappearance of a crystallisation peak $T_{c}$. The melting exotherm $T_{m}$ decreases in intensity and its maximum value increases from $387^{\circ} \mathrm{C}$ (unworn) to $391^{\circ} \mathrm{C}$ (after sliding at 140 to $180^{\circ} \mathrm{C}$ ) in parallel to the formation of crystalline and strongly cross-linked structures. The recrystallisation peak during cooling disappears because crystal 
(a)

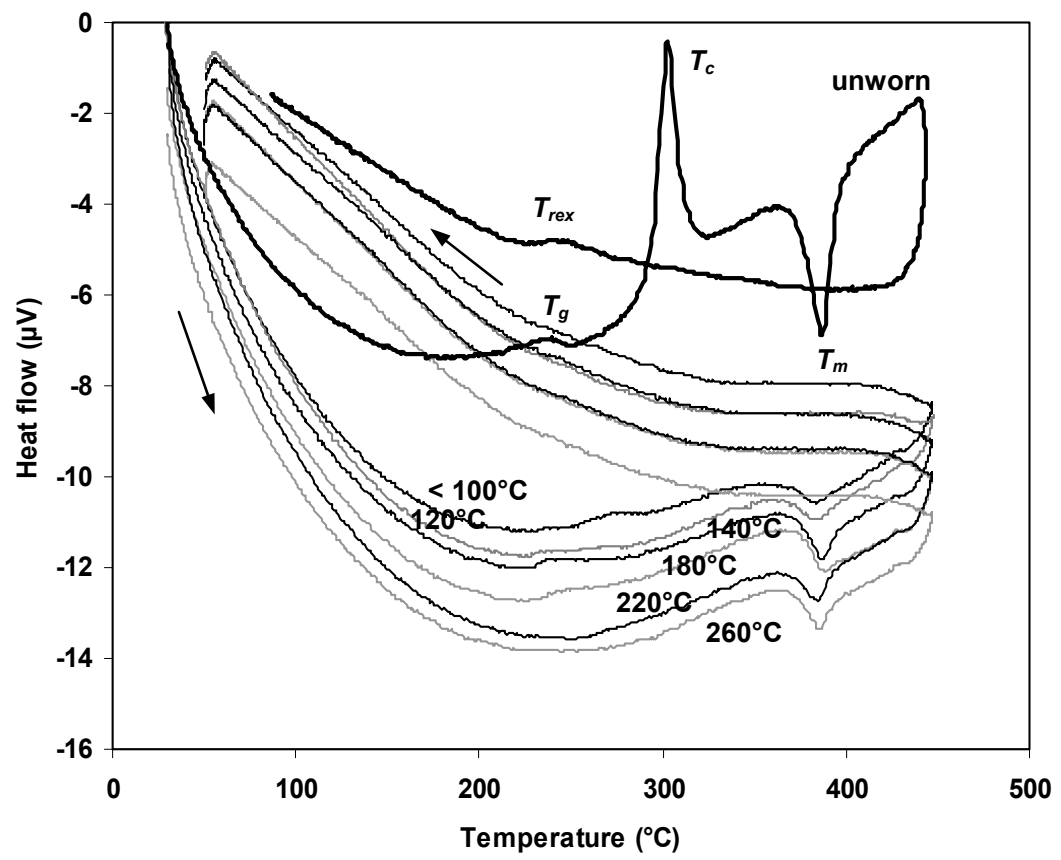

(b)

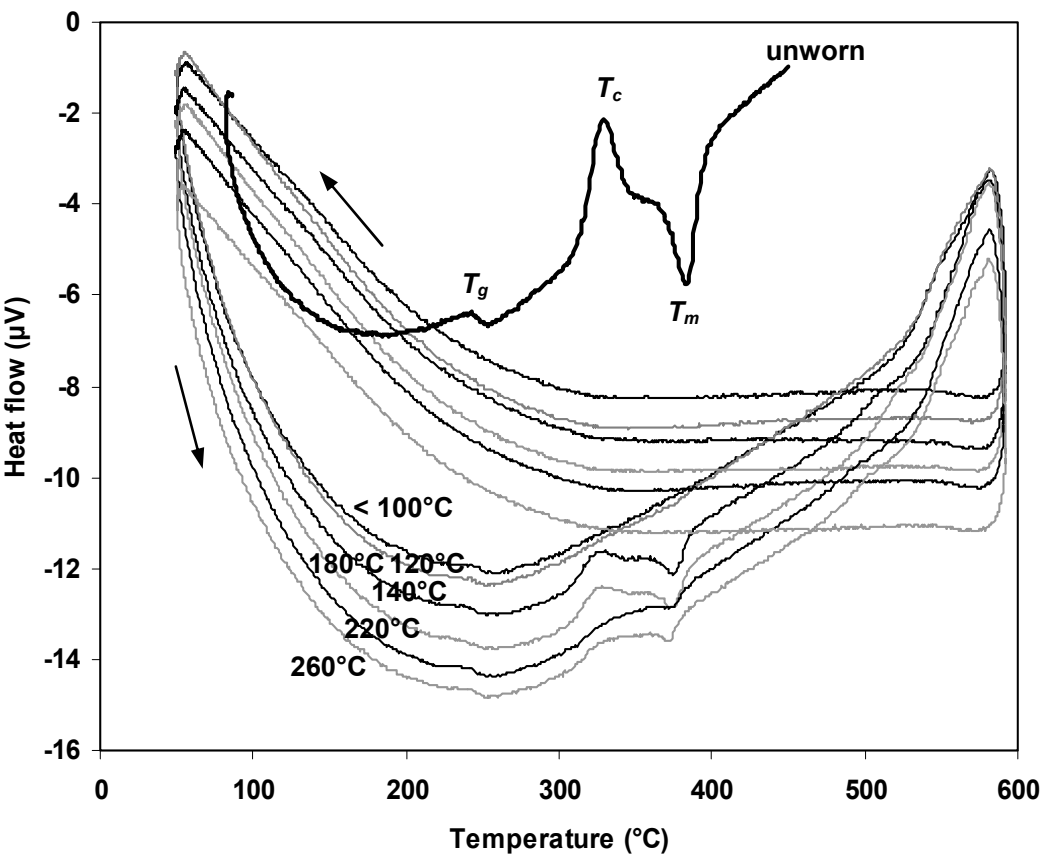

Figure 5: Differential thermal analysis of TP wear debris after sliding at 60 to $260^{\circ} \mathrm{C}$, (a) first DTA heating cycle, (b) second DTA heating cycle. 
nucleation lacks in the modified amorphous phase. The conclusion that the amorphous phase modifies under sliding agrees to visual observations that debris particles change from transparent to opaque yellow colour. Debris becomes brittle (and consequently acting more abrasive) after sliding in parallel to the behaviour of sintered polyimides. The second heating step in DTA (Figure 5(b)) shows that the structural modifications of the amorphous phase are partially reversible after a first heating step.

The transition zones in tribological properties of TP (Figure 1(b)) are compared to wear debris evaluation and parallel transitions in thermo-analytical analysis are found:

- After sliding at 100 to $120^{\circ} \mathrm{C}$ (increasing friction), dark coloured particles indicate chemical degradation by hydrolysis. This is confirmed by TGA analysis showing lowest thermal stability for $120^{\circ} \mathrm{C}$ wear debris.

- After sliding at 120 to $180^{\circ} \mathrm{C}$ (decreasing friction), flake-like particles indicate an increase in polyimide strength by imidisation. This is confirmed by TGA analysis showing high thermal stability of those particles. The DTA analysis also indicates crystallisation or cross-linking of debris particles after 120 to $180^{\circ} \mathrm{C}$ sliding tests, although at lower temperature relatively to unworn TP.

- After sliding at 220 to $260^{\circ} \mathrm{C}$ (increasing friction), rolled debris particles indicate melting. As those particles are rapidly removed out of the sliding interface, TGA analysis shows high thermal stability.

\section{Thermo-analytical mass spectroscopy (MS) of sintered wear debris}

The emission of gaseous species during thermal decomposition of SP wear debris is analysed with a mass spectrometer coupled to DTA/TGA measurements. One single heating step from 23 to $600^{\circ} \mathrm{C}$ at $20^{\circ} \mathrm{C} / \mathrm{min}$ is applied, using argon carrier stream. It will demonstrate that the instrumentation is sensitive to detect water volatilisation (only $1 \%$ weight loss) and confirms that the endothermic reaction at $180^{\circ} \mathrm{C}$ is surely related to dehydration. Other degradation products are characterised and have lower intensity, which further decreases when the sliding temperature was higher. Some spectra for SP wear debris after sliding at $50 \mathrm{~N}, 0.3 \mathrm{~m} / \mathrm{s}$ and $100,180,260^{\circ} \mathrm{C}$, are given in Figure 7 . Spectra represent the volatilisation intensity for a specific emission product as a function of the heating temperature. Each decomposition product is characterised by its atomic mass unit (a.m.u.) and intensities are related to the ion current (A) in the mass detector (scaled to sample weight), which is proportional to the concentration of decomposition product in the carrier stream. 


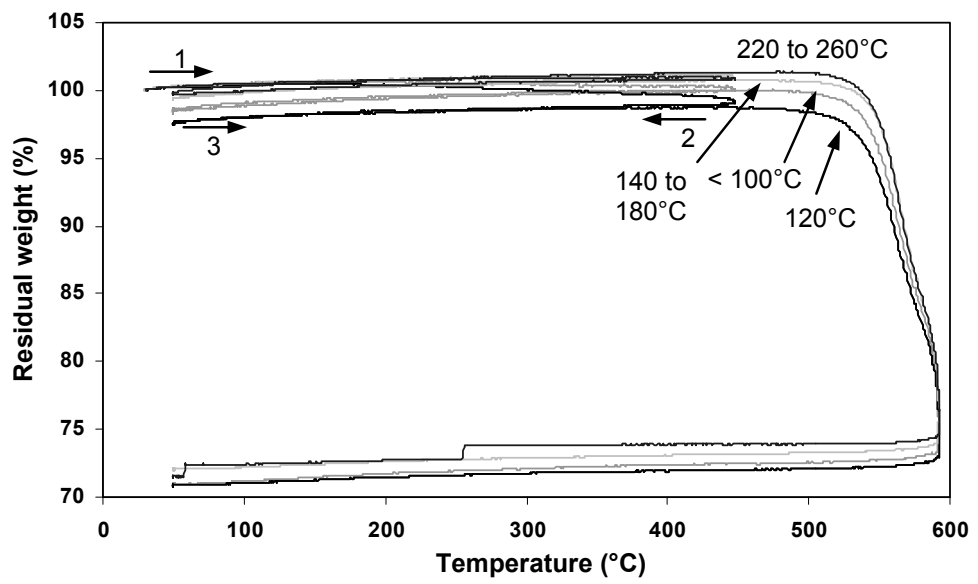

Figure 6: Thermogravimetric (TGA) analysis of TP wear debris after sliding at 60 to $260^{\circ} \mathrm{C}$ over a heating cycle 1 , cooling cycle 2 , heating cycle 3 .

(a)

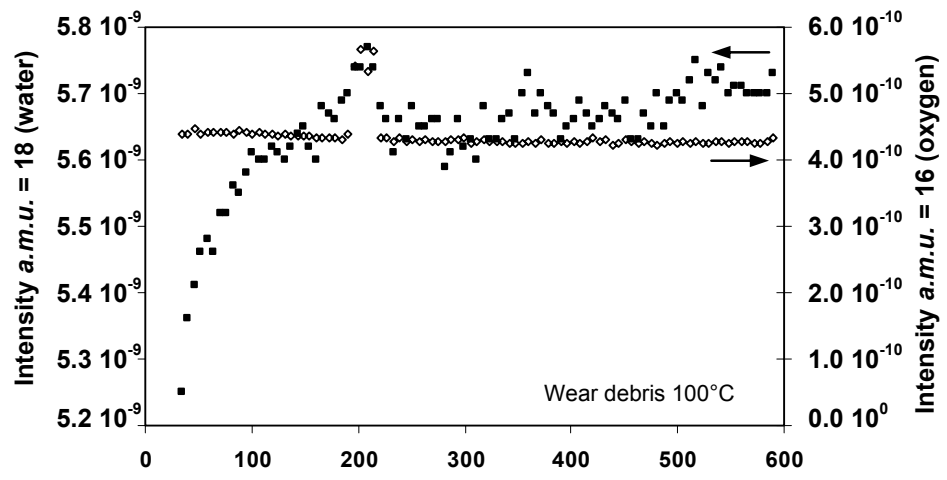

(b)

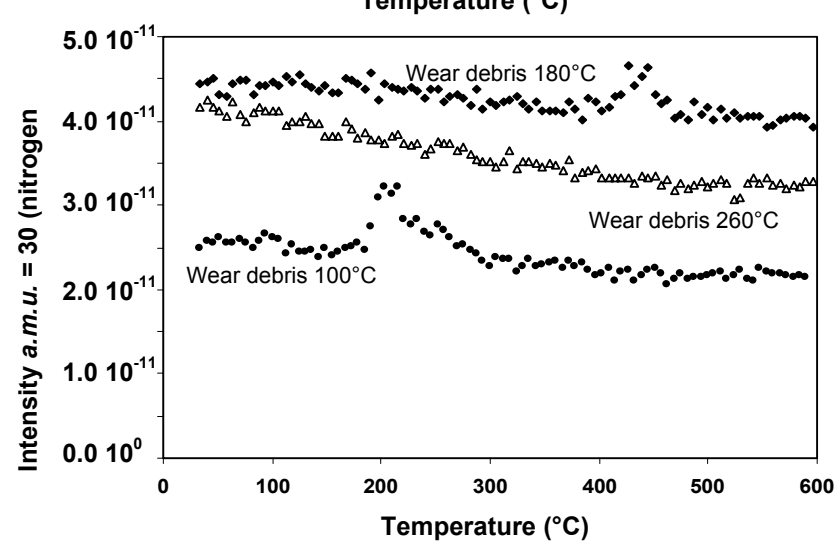

Figure 7: $\quad$ Mass spectroscopy for sintered polyimide wear debris. 
Most important decomposition fraction for tribological performance is the production of water (a.m.u. $=18$, Figure 7(a)). Water volatilisation occurs at 180 to $200^{\circ} \mathrm{C}$ heating temperatures as a peak intensity for the debris samples after $100^{\circ} \mathrm{C}$ sliding or a maximum intensity for debris samples after 180 and $260^{\circ} \mathrm{C}$ sliding (not shown). Water volatilisation at 200 to $600^{\circ} \mathrm{C}$ heating temperatures depends on the sliding temperatures, showing: (i) a constant or increasing tendency of water volatilisation for $100^{\circ} \mathrm{C}$ debris indicating progressive imidisation during heating, and (ii) a decreasing trend for 180 to $260^{\circ} \mathrm{C}$ wear debris indicating that debris is more inert by imidisation during sliding. The peak in water emission for high temperature wear debris broadens through variations in structure (and molecular weight) after wear. Water volatilisation agrees to the previously noted shift of dehydration temperature $T_{\text {hydrat }}$ in DTA thermographs, rising for debris after 180 to $260^{\circ} \mathrm{C}$ sliding. A second small peak in a.m.u. $=18$ intensities for debris after $100^{\circ} \mathrm{C}$ sliding occurs at $380^{\circ} \mathrm{C}$ and corresponds to small weight loss. The oxygen intensity $($ a.m.u. $=16)$ is plotted over the intensities of water volatilisation in Figure 7(a) and confirms that dehydration or water condensation is responsible for the noted endothermic reaction at $180^{\circ} \mathrm{C}$.

The nitrogen-monoxide NO fraction (a.m.u. = 30, Figure 7(b)) has similar features to nitrogen $N$ fraction $(a . m . u$. $=14)$. It is firstly stressed that the concentration of released nitrogen is a factor $10^{-2}$ to $10^{-3}$ smaller than water concentrations. The decomposition of polyimide wear debris into nitrogen monoxide is postponed and finally disappears with increasing sliding temperatures through formation of a strong imide structure after sliding.

\section{Conclusions}

For sintered polyimides, hydrolysis and imidisation reveals from thermoanalytical analysis of wear debris and explains transitions in friction and wear. For thermoplastic polyimides, crystallisation and melting effects are most important.

\section{References}

[1] Jacko M.G., Tsang P.H.S., Rhee S.K., Wear debris compaction and friction film formation of polymer composites, Wear, 133, pp. 23-38, 1989.

[2] Sharf T.W., Singer I.L., Monitoring transfer films and friction instabilities with in situ Raman tribometry, Tribology Letters, 14, pp. 3-8, 2003.

[3] Tewari U.S., Bijwe J., Tribological behaviour of polyimides. Polyimides, ed. M. Dekker, Marcel Dekker: New York, pp. 533-583, 1996.

[4] Nagai N., Hironaka T., Study of interaction between polyimide and $\mathrm{Cu}$ under high humidity condition, Applied Surface Science, 171, pp. 101-105, 2001. 